Reagan administration and the economic recession was only just being felt by the academic sector. Another survey in two years' time could reveal a very different picture.

In the part of the survey relating to publishing it was found that US publishers produced a total of 20,400 serial titles in 1980 , an increase of approximately 21 per cent over the 16,900 serial titles published in 1976. The most dramatic change was in the number of article reprints sold, rising from 16.2 million in 1976 to 34.4 million in 1980 - a clear demonstration of the trend towards using copies of single articles rather than whole issues.

One curious result of the survey was the huge discrepancy between interlibrary loan requests received and the much smaller number placed, which suggests that librarians often try two or more other libraries to find a source. This may partly explain the high "real" cost of an interlibrary loan, estimated by King Research in an earlier study to be between $\$ 15$ and $\$ 20$ for an article. In Britain the system is more efficient in that librarians almost automatically go to one central source, the British Library Lending Division which through economies of scale is able to supply photocopies at low rates.

It is likely that researchers faced with declining library holdings and ever more titles will increasingly rely on copies of single articles identified through secondary services such as Current Contents, abstracts journals and now on-line searches. But they are supplied by a relatively cumbersome system where a source often has to be found at some expense, and the actual journal is taken off the shelves and photocopied with the document then going through the mail for delivery through the user's library.

Publishers and librarians are, therefore, looking towards new systems of document delivery based on information technology. For example, it is possible to store the full image of each page in compressed digital form on optical discs for retrieval and rapid print out. It is also possible but not yet economically feasible to transmit the digital form via a satellite for printing out in the user's library. Such is the progress of information technology that the late J.D. Bernal's dream - making available to individuals only copies of those articles in which they have declared an interest - may well become a reality within several years. A more efficient form of document delivery now made possible by the new technology should enable document delivery centres to supply libraries quickly and at lower rates, yet still at sufficient margins to enable them to pass back vital copyright revenue to the original publishers. The emergence of new titles catering for new needs and the survival of existing titles could depend on it.

Robert Campbell is a Director of Blackwell Scientific Publications.

\title{
New journals June 1980 to May 1981
}

THE new journals review issue is intended as a service to potential subscribers (especially librarians) and authors, and also to publishers who may welcome comment on and publicity for their infant journals. How informative and comprehensive a survey these pages provide depends in part upon the reviewers, but also upon the cooperation of publishers. Unfortunately, this is not always forthcoming; not through obstructiveness but perhaps because of insufficient interest in many promotions departments.

Criteria for journals to be considered for inclusion in this issue were circulated to publishers earlier this year and were also printed in Nature. They were that:

(i) the first number appeared, or the journal was re-titled, between June 1980 and May 1981 (although journals not covered in the previous review issue Nature 293, 341-369; 1981 - were also considered);

(ii) the journal appears at least three times a year;

(iii) the main language used is English;

(iv) where possible four issues should be made available for review, the first, the most recent, plus two others.

The 1981 journals review issue covered new publications appearing up to May of 1980, and the second cut-off date, May 1981 , allows for enough issues of a journal to have been published for a reasonable sample to be available for judgement. Equally a spread of four distinct issues is taken as being the minimum on which reviewers' comments can be based.

Several journals known to satisfy the above criteria were not submitted for review, or arrived only in August or September, and therefore are not covered in this issue. And those publishers who sent in four identical issues of, for example, Vol. 1. No. 1, are less likely to find their journal reviewed here.

Disappointed editors should note, however, that it proved impossible to find reviewers for some doubtless worthy journals and that other titles were considered to be of marginal interest to Nature's audience. Of the larger publishers Elsevier Biomedical and Alan R. Liss are to be thanked for their speed and efficiency in supplying the material requested.

Although not comprehensive, over 60 journals are reviewed. The brief given to reviewers was to limit themselves to comment on the publications sent to them for review, and to avoid discussion of general questions of periodical publishing.

As last year, the preponderance of journals in the biological sciences reflects the bias of the material submitted for review and the shortest possible abbreviations of titles have been used. Opinions expressed in the reviews are based on a sample, and apply to mid-1982 at the latest. Details of editors and frequency of publication, and the basic annual subscription rates appearing at the top of each review are given in most instances for 1983. These details are not complete in all cases, and readers should check subscription rates in particular with the publisher concerned. The reviews of journals begin on p. 497 .

\section{Index to journals reviewed}

American Journal of Primatology

American Journal of Reproductive Immunology

Amphibia-Reptilia

Antiviral Research

Appetite

Applied Biochemistry and Biotechnology

Applied Catalysis

Aquatic Toxicology

Behaviour Analysis Letters

Bjochemistry International

Biological Oceanography

Bioscience Reports

Bulletin of Science, Technology and Society Cell Motility

Cellular and Molecular Neurobiology

Chinese Astronomy and Astrophysics Chinese Physics

The Clinical Biochemist: Reviews

Clinical Physics and Physiological Measurement

Clinical Physiology

Cognition and Brain Theory

Comments on Molecular and Cellular Biophysics

Developmental Pharmacology and Therapeutics

Environmental Monitoring and Assessment European Applied Research Reports:

Environment and Natural Resources Section

Immunology Today

Insect Science and its Application

International Journal of Andrology

International Journal of Clinical Pharmacology Research

International Reviews in Physical Chemistry

Journal of Andrology

Journal of Applied Biochemistry

Journal of Astrophysics and Astronomy

The Journal of Biosciences

Journal of Cerebral Blood Flow and Metabolism

Journal of Climatology

Journal of Computational Chemistry

Journal of Fusion Energy

Journal of Interferon Research

Journal of Molecular and Applied Genetics

Journal of Neuroimmunology

The Journal of Neuroscience

Journal of Vertebrate Palcontology

Marine Ecology

Molecular and Cellular Biology

Mutation Research Letters

Neuropeptides

Nordic Journal of Botany

Nuclear Medicinc Communications

Nuclear Technology/Fusion

Pediatric Pharmacology

Peptides

PhysicoChemical Hydrodynamics

The Prostate

Psychoenergetics

Radiation Protection Dosimetry

Regulatory Peptides

Soviet Progress in Virology

Teratogenesis, Carcinogenesis,

and Mutagenesis

Theochem

Trends in Analytical Chemistry

Zeolites 